\title{
2006-1255: LET IT ROLL WITH YESS!
}

Taryn Bayles, University of Maryland-Baltimore County

Taryn Bayles, Ph.D. is a Professor the Practice of Chemical Engineering in the Chemical \& Biochemical Engineering Department at UMBC, where she teaches Introduction to Engineering Design and various Chemical Engineering courses. She has spent half of her career working in industry and the other half in academia. Over the last three years, she has received over $\$ 3 \mathrm{M}$ of NSF funding in Engineering Education \& Outreach to develop hands-on curriculum to increase the interest, participation, recruitment, and retention of students in engineering and science. She has been recognized with several teaching and mentoring awards and the 2006 USM Regents Award for Collaboration in Public Service.

\section{Ted Foster, University of Maryland-Baltimore County}

Ted Foster, Ph.D. is Assistant Dean of the UMBC College of Engineering and Information Technology, where he coordinates accreditation activities and directs graduate programs in Systems Engineering and Engineering Management. Prior to coming to UMBC, he had a 36-year career at Westinghouse and Northrop Grumman, managing research and advanced development in microelectronics and microwave technology for modern radar systems.

\section{Dean Sheridan, Glen Elg High School, Howard County Public Schools, Maryland}

Dean Sheridan has been an engineering design, mathematics and computing teacher at Glenelg High School for the last 22 years. In addition he is an Adjunct Professor at Howard Community College in Astronomy, Physics, Chemistry and Computer related instruction. Under his leadership, his students have been regional winners in the US First Robotics Competition for the last four years and he has served as the Director of the YESS program since 2002. He also coaches Varsity Soccer, Indoor Track, Softball, Gymnastics and Wrestling. Mr. Sheridan has also been recognized with various Outstanding Teaching awards.

\section{Carolyn Parker, George Washington University}

Carolyn Parker is an Assistant Research Professor in the Department of Teacher Preparation and Special Education in the Graduate School of Education at the George Washington University. She has a doctorate in Curriculum and Instruction-Science Education from the University of Maryland College Park. Carolyn was a high school science teacher. Her research interests are gender and equity in science and technology. 


\title{
Let's Roll with YESS!
}

\begin{abstract}
YESS (Young Engineers and Scientists Seminars http://www.yesshem.com) is an enrichment program for gifted and talented high school students from the Baltimore/Washington areas who have a strong aptitude in mathematics and science fields. Letters are sent to Science, Mathematics, Technology and Engineering High School teachers asking them to nominate students for participation in the program. This program was founded in 2002 and is funded by the Historical Electronics Museum with a grant from Northrop Grumman. YESS has presented speakers on topics as diverse as plasma physics, stealth radar, biomedical imagery, super computers/micro technology, aeronautical engineering, astrophysics and satellite reconnaissance.
\end{abstract}

In 2004, the program was revised from a strictly seminar series, to a hands-on program designed to help students understand the engineering design process. Two-hour sessions are held biweekly and students learn how to go from brainstorming to designing, building, and testing. For the 2005 YESS program the over-arching project, performed in teams, was to design a mousetrap vehicle which had to meet various design criteria, which include maximizing distance traveled, pulling capability, speed over a specified distance, and stopping ability at a specified distance. The YESS program is a miniature version of the Introduction to Engineering course at the University of Maryland, Baltimore County. At each seminar the high school students learn engineering fundamentals that relate to their design project, followed by hands-on mini design challenges. The presentations given by technical experts include: Who Wants to be an Engineer?, Introduction to Engineering Design: Project Based Learning, The Engineering Method, Vehicle Design, Power and Energy Conversion: An Engineering Perspective, and Computer Modeling Techniques. The mini design challenges are related to different aspects of the over-arching design project and the teams compete for prizes provided by Northrop Grumman. Scholarship awards were made to the top four teams for the mousetrap vehicle design competition.

A mini-grant from the NSF funded Conducting Rigorous Research Education: Creating a Community of Practice (DUE-0341127) has been received and is being used as incentive to the students to submit surveys before and after participating in the program. The purpose of the surveys was to measure how the instruction of pre-college students in the engineering design process using project based learning with hands-on activities impacts engineering knowledge and decisions to study engineering. The students completed pre- and post-surveys measuring interest, attitude and knowledge of the engineering design process and the underlying principles associated with a successful design solution. In addition, each team was required to keep a design notebook to document the evolution of the final design. Part of the funding received is also being used for the assessment of the data. The preliminary results of these findings have been complied and the final results will be presented in June.

\section{Background}

The Mission of the Historical Electronics Museum is to educate industry, government, students and the general public on the evolution and the importance of defense and commercial 
electronics of the past through the exhibition and interpretation of historically significant artifacts and documents related to electronics technology ${ }^{1}$. The education goal of the museum is to provide visitors with an understanding of the basic concept of electronics and an appreciation of evolutionary milestones of sophisticated electronics systems. In support of these objectives, the museum's priority is to provide a motivational environment for students of all ages to gain an understanding of basic engineering and the career opportunities available through higher education. With this priority in mind, the Historical Electronic Museum started the Young Engineers and Scientist Seminars (YESS) program in the fall of 2002, for highly gifted high school students from the Baltimore/Washington areas who have a strong aptitude in mathematics or science. The first two years of the program consisted of a series of dynamic seminars on topics as diverse as plasma physics, stealth astrophysics and satellite reconnaissance. In the fall 2003, one of the authors co-presented one of the seminars on "Careers in Engineering and Introduction to Engineering Design". This seminar involved a variety of hands-on activities that the students rated favorably at the end of the seminar series. Despite having excellent speakers during the 2003-4 program year, the student attendance was erratic, and varied from 23 to 55, with only one student attending all of the seminars. The Board of Directors of the Historical Electronics Museum met over the summer of 2004, to strategize as how to improve the attendance of the YESS program.

Members of the Board of Directors of the museum were familiar with the Introduction to Engineering Design course at the University of Maryland Baltimore County (UMBC) (which the authors teach). Over the last five years, this course has been revised from a traditional lecture and design-on-paper course, to an active learning lecture and project-based learning engineering design course ${ }^{2}$. The design teams are required not only to research, design, construct, evaluate, test and present their product, but also to develop a mathematical model of their product's performance. It is important that the students have a fun, yet inexpensive project to design and build, but they must also develop a mathematical understanding of the fundamental engineering principles that make their design work. Successful engineering design projects have included human-powered pumps, water balloon launching devices, hot air balloons, wooden block transport devices, hemodialysis systems, and chemically-powered vehicles. Therefore, the Board of Directors asked one of the co-authors to co-lead the seminar series for the fall of 2004, by offering a scaled-down version of UMBC's Introduction to Engineering Design course to help the high students understand the engineering method.

In August, letters were sent to $\underline{\text { Science, }}$ Technology, Engineering, and $\underline{\text { Mathematics (STEM) }}$ High School coordinators inviting them to nominate students for the program (teachers and parents were also invited to attend the program) from Anne Arundel, Howard, Baltimore, and Carroll counties, as well as Baltimore City. The new hands-on approach to the program was described in the letter and a new website ${ }^{3}$ was created to feature the YESS program. The website was updated throughout the fall with information that the students needed to create their design projects, as well as copies of the PowerPoint presentations from each session and pictures of the hands-on activities. IRB approval for this project was secured and release forms signed by the student and/or parent/guardian were collected from the students.

In an effort to assess the effectiveness of the YESS seminar, survey instruments were created to capture self-reported data, including demographic information, parent's occupations, interest in science and engineering, level of understanding of key content areas, as well as measures of confidence in math and science and general attitudes and expectations for the seminar series. 
Students completed pretest surveys on the third night of the series and post-test surveys on the last night. Much to our disappointment IRB approval for our project took in excess of eight weeks, and therefore we were unable to have the students complete the pre surveys until almost mid-way through the program. Twenty students completed both set of surveys, 8 completed pretest surveys only and 28 completed posttest surveys only. Since pretest and posttest instruments were matched, demographic questions were omitted from the posttest form. Based on the pretest data $(n=28), 79 \%$ of participants were men, $76 \%$ were White, $12 \%$ were Asian, $6 \%$ were African American, $3 \%$ Native American and $3 \%$ chose the category Other. Half of the students were seniors, $32 \%$ were juniors, $7 \%$ sophomores and $11 \%$ were freshmen. Most of the respondents were from Anne Arundel County (60\%), followed by Howard County (28\%), Hartford County (8\%) and Baltimore County (4\%), all in Maryland.

Results of the 2004 YESS program ${ }^{4}$ were presented at the 2005 ASEE Annual Conference \& Exposition. The attendance in the 2004 program ranged from 50 to 72 students (with an average of 63 students at each session). Eleven students attended all of the seminars, and fifty students attended at least two-thirds of the seminars during the 2004 YESS program. In addition, there were 10-15 visitors (high school teachers and parents) at each seminar. This was an improvement over the 2003 program where attendance ranged from 23 to 55 students per seminar, with only one student attending all of the seminars. Comments from many of the students and parents during the YESS program indicated that the hands-on activities and the design project were enjoyable additions to the seminars. The Board of Directors expressed their delight with the improved attendance and format of the YESS program and asked the co-leaders of the 2004 YESS program to lead the 2005 YESS program again with this revised hand-on approach. A full description of the 2004 YESS program was highlighted in the Historical Electronics Museum, Reflections newsletter ${ }^{5}$.

The 2005 program was similar to the 2004 program and was designed to have the high school students learn how to go from brainstorming to designing, building, and testing. The overarching project, performed in teams, was to design a mousetrap vehicle which had to meet various design criteria, which include maximizing distance traveled, pulling capability, speed over a specified distance, and stopping ability at a specified distance. During each seminar, presentations on engineering topics related to the design project were provided; also at each seminar a short presentation was made to provide design considerations for the mousetrap vehicle. At the conclusion of each seminar a short hands-on mini design challenge was conducted and the student teams competed for prizes. The program met every other week from September 22 through December 14, from 7 PM to 9 PM. There was no charge for the program and complementary food (usually subs or pizza) was provided at 6 PM. Prizes were awarded each evening for various hands-on activities (which will be described below), and cash awards were made for the final mouse trap vehicle design competition. The prizes for the mini design challenges were provided by Northrop Grumman and consisted of Northrop Grumman logo ball caps, visors, bags, playing cards, key chains, etc. The Young Engineers and Scientists Seminars program was funded by the Historical Electronics Museum in conjunction with a grant from the Northrop Grumman Litton Foundation. Also new for the 2005 YESS program was the addition of guided tours of the Historical Electronics Museum (10/05/05) and the Northrop Grumman site $(10 / 14 / 05)$ prior to the complementary food portion of the program. The following are descriptions of each of the seminars:

\section{Introduction to Engineering}


At the first evening of the YESS program, an overview of the Engineering profession was presented (greatest engineering achievements of the $20^{\text {th }}$ century, what is engineering, salaries, work environment, opportunities, types of engineers, etc.). This was followed by the $\boldsymbol{W h o}$ Wants to be an Engineer game ${ }^{6}$ created by Professor David Silverstein from the University of Kentucky - Paducah, where the students had to match answers to engineering questions. The students received "YESS bucks" for each correct answer and this proved to be a very successful activity. This was followed by an overview of the Introduction to Engineering Design course at UMBC. Videos of the various design projects were also featured to give the students a better understanding of what will be expected of them when studying engineering. UMBC's Office of Information Technology has filmed the design process over the course of the semester and has produced a video ("Video: Teamwork, Design, and Making Things Work! Undergraduate Design Class" produced by Bob Kuhlmann and Damion Wilson of UMBC's New Media Studio http://www.umbc.edu/engineering/cbe/ ). The hands-on activity for this first evening is described below and was adapted from the ASME website ${ }^{7}$ :

\section{Introduction to Engineering Design Challenge: Let It Launch!!!}

Design and construct a mechanism that launches a ping pong ball a maximum distance and successfully hits a target (14 inches in diameter) which was placed five feet from the launching table. Each mechanism must be constructed ONLY with the provided materials. Two launches were allowed for distance (counting only the furthest distance) and four launches at the target (counting each of the four launches for accuracy). The ping pong ball had to be launched by one selected team member from the constructed mechanism, which had to be free standing and not taped to the launching table or floor starting position. Thirty minutes was allocated for the design, planning and construction phase.

- The materials provided were:

- 3 plastic cups

- 10 tongue depressors

- 8 rubber bands

- 1 plastic spoon

- 8 thumb tacks

- 3 small dowel rods

- mini clothes pin

- 1 roll of making tape

- 1 ping pong ball

- 1 paper bag

The contest winner (bragging rights) was determined using the following formula:

$$
\mathbf{X} * \mathbf{Y}
$$

where: $\mathrm{X}$ - distance in inches (best of two)

$\mathrm{Y}$ - accuracy percentage (of the four launches) 
The goal of this activity was for the students to begin to think about the connection between mathematics and engineering. Figure 1 illustrates the distance and accuracy competitions for the Let it Launch!!! mini design challenge.

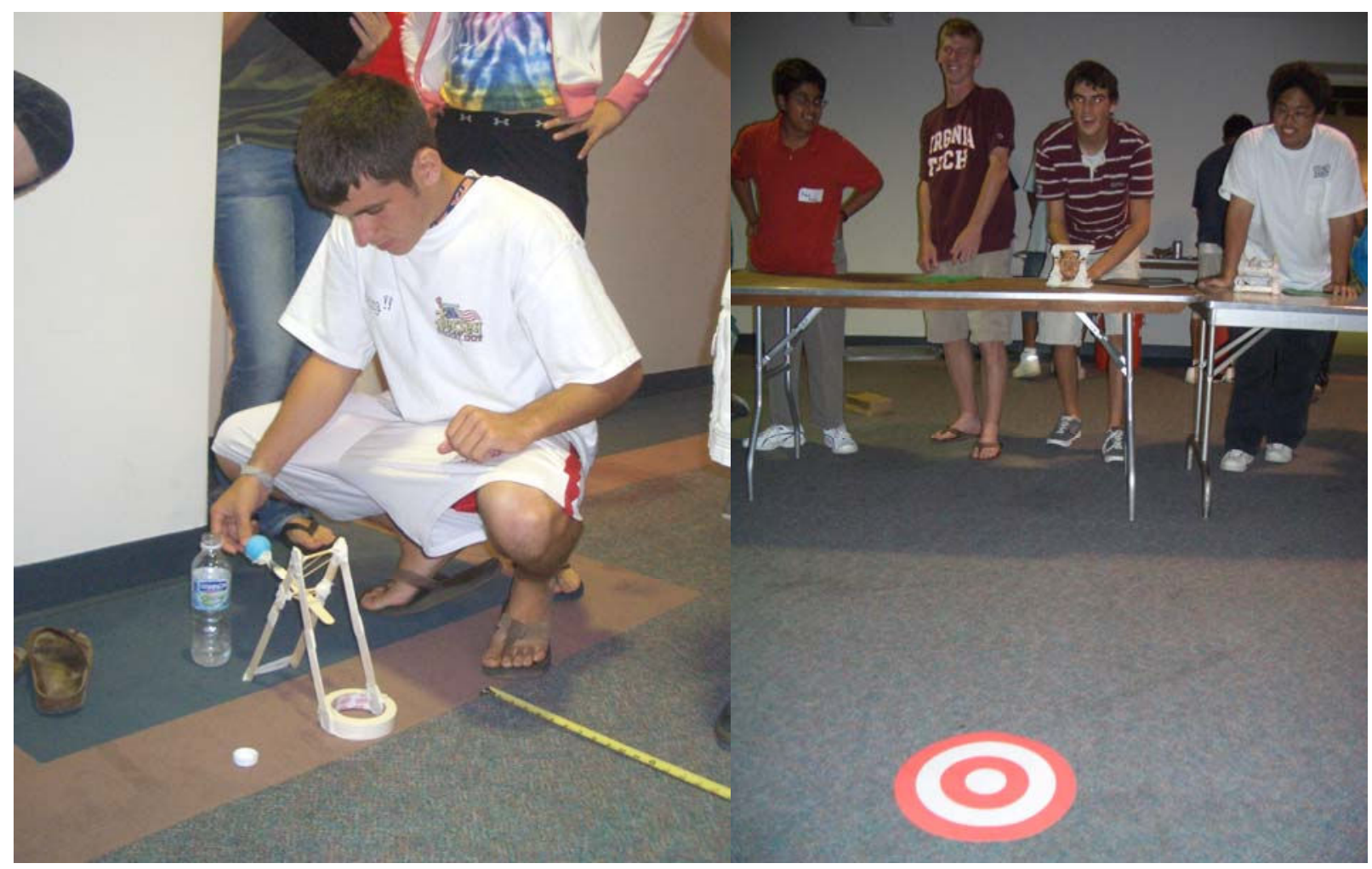

Figure 1: Let it Launch!!! activity

\section{The Engineering Method}

On October 5, Dr. Roland Anders, Chief Scientist of Space Systems, at Northrop Grumman delivered an excellent presentation on the engineering method, innovative engineering feats, and the importance of planning during the engineering process. The mousetrap vehicle design project was also introduced at this seminar (and will be described below). A ZOOM Across the Finish Line!!! mini design challenge (which was adapted from http://www.cmesa.org) concluded the evening:

\section{ZOOM Across the Finish Line!!!}

The goal of this project was to develop an appreciation for working in teams, designing a vehicle on paper, and then constructing and racing the vehicle, under a time constraint. The objective was to construct and race a self propelled vehicle using only the materials provided. Each team had 20 minutes to design and plan, during which none of the pieces could be assembled and only paper and pencil were allowed to be used. This was followed by the build/construction and race phase. The first three self-propelled vehicles across the finish line ( 8 feet away) were awarded prizes. Materials provided included: two pieces of paper, 1 pencil, 3 paper clips, 1 butterfly clip, 2 straws, 3 large index cars 
(one with grid-lines), 3 rubber bands, 1 roll of masking tape, and 1 pair of scissors. Successful designs are shown in Figure 2.

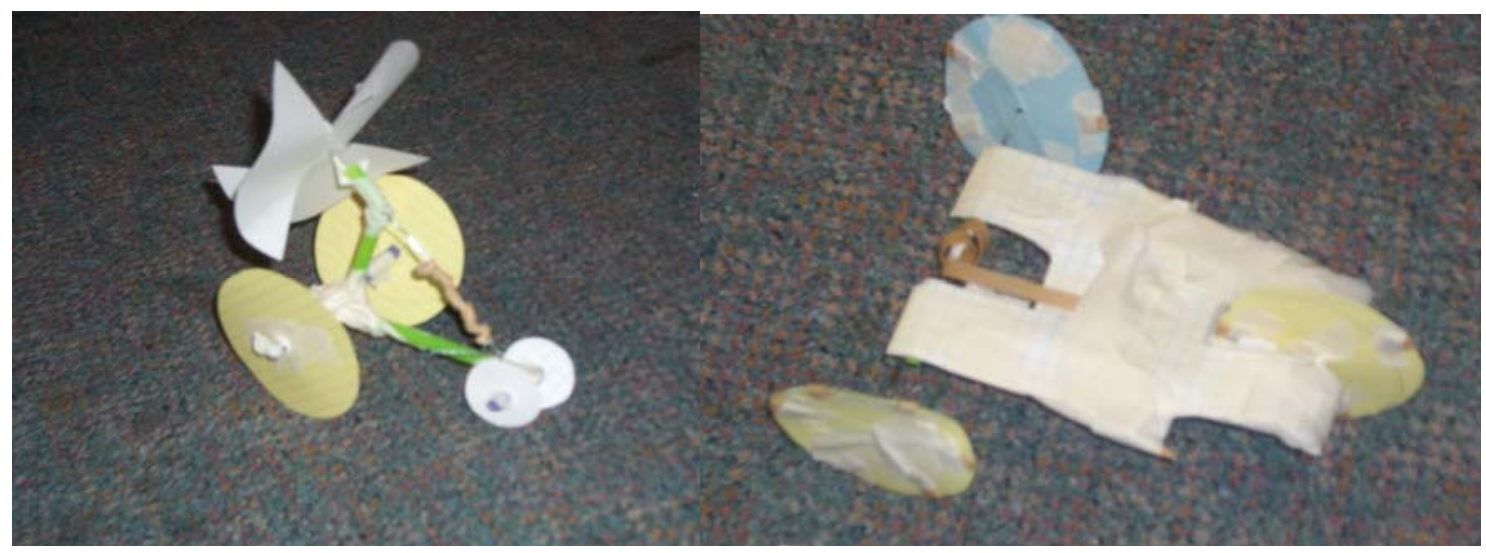

Figure 2: Zoom Across the Finish Line!!! Successful Designs

\section{The Mousetrap Vehicle Design Project: Let's Roll with YESS!!!}

The YESS program design project was to design, construct, predict the performance, test and evaluate a multi-functional mousetrap vehicle. The mousetrap vehicle project was selected since the materials for a successful design project are inexpensive and the underlying concepts of the multi-functional requirements lend themselves to a wide variety of designs. The mousetrap vehicle was powered by a Victor ${ }^{\circledR}$ brand mousetrap which was provided by the Chemical and

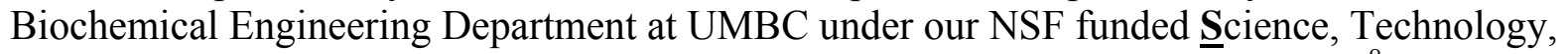
Engineering and Mathematics, Talent Expansion Program (STEP-DUE-0230148) ${ }^{8}$. The mouse trap vehicle had to compete in each of the four categories:

- Maximum distance traveled (measured in feet)

- Maximum load pulled over a distance of three feet

- Maximum speed over 20 foot distance

- Accuracy of stopping at 8 feet (measured in inches greater than or less than the 8 foot mark)

The primary criterion for this design project is SAFETY; the vehicle must operate without any hazards. It had to be constructed from materials found around their home. The teams were not allowed to purchase anything for the construction of the vehicle. Various sets of wheels were allowed during each phase of the competition: however, all of the wheels must be carried with the vehicle for each of the runs (distance, load, speed and stopping) of the competition. In addition, the following guidelines were placed on the construction:

- The mousetrap mechanism could not be altered or modified.

- Only the mousetrap could be used to power the vehicle.

- No use of rubber bands or anything elastic to attach from the mousetrap to the axles of the vehicle.

- Either axle, or both, may be used as the drive axle(s). 
- The entire vehicle must start behind the designated START line. All vehicles must start from the same point, however, they do not have to start in the same orientation (they may start angled with respect to the START line.

Vehicle performance: "Bragging rights" for vehicle performance were assessed using the performance metric:

\section{Distance traveled (in feet) $x$ Load Index $x$ Speed Index $x$ Stopping Index}

The load index is calculated using:

Your Team Design Vehicle Load Pulled (in grams) a distance of three feet

YESS Program Maximum Load Pulled (in grams) a distance of three feet

The speed index is calculated using:

Your Team Design Vehicle Speed ft/sec

YESS Program Maximum Speed ft/sec

Where stopping index is calculated using:

$$
1.0-\left|\frac{\text { Stopping distance measured in inches }-96 \text { inches }}{24 \text { inches }}\right|
$$

Note: If the vehicle does not stop within 1.9 feet of the required 8 foot stopping distance, a default stopping index of 0.05 is assigned. The minimum design criteria (so that the vehicle can qualify to be considered for the competition) is that it must travel at least 20 feet and it must also be able to pull at least a load of 100 grams at least three feet.

In addition, each team was expected to complete a design notebook ${ }^{9}$ as a log of the evolution of their designs. The notebooks were provided to the YESS teams by the Chemical and

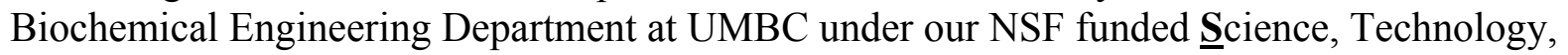
Engineering and Mathematics, Talent Expansion Program (STEP-DUE-0230148). This grant also funded the materials used in each of the mini design challenges.

\section{Vehicle Design}

Dr. Bill Wood, Assistant Professor of Mechanical Engineering provided an excellent overview of Vehicle Design. He highlighted the UMBC Mini Baja ${ }^{10}$ vehicle design \& competition and contrasted the Mini Baja design considerations to what the YESS program students needed to consider for their mousetrap vehicle design. This presentation was followed by the Let's Sail Away mini design challenge:

Let's Sail Away!!! 
The goal of the project was to construct a vehicle made from K'NEX parts that traversed a maximum distance while minimizing the vehicle cost (a 'cost' was assigned to each K'NEX part). Some of the innovative designs are shown in Figure 3. The vehicles were powered by a box fan. The bragging rights associated with the mini design challenge were:

\section{Total Distance Traveled (inches) $\mathrm{X} \quad$ Minimum YESS Team Cost Your Team Cost}

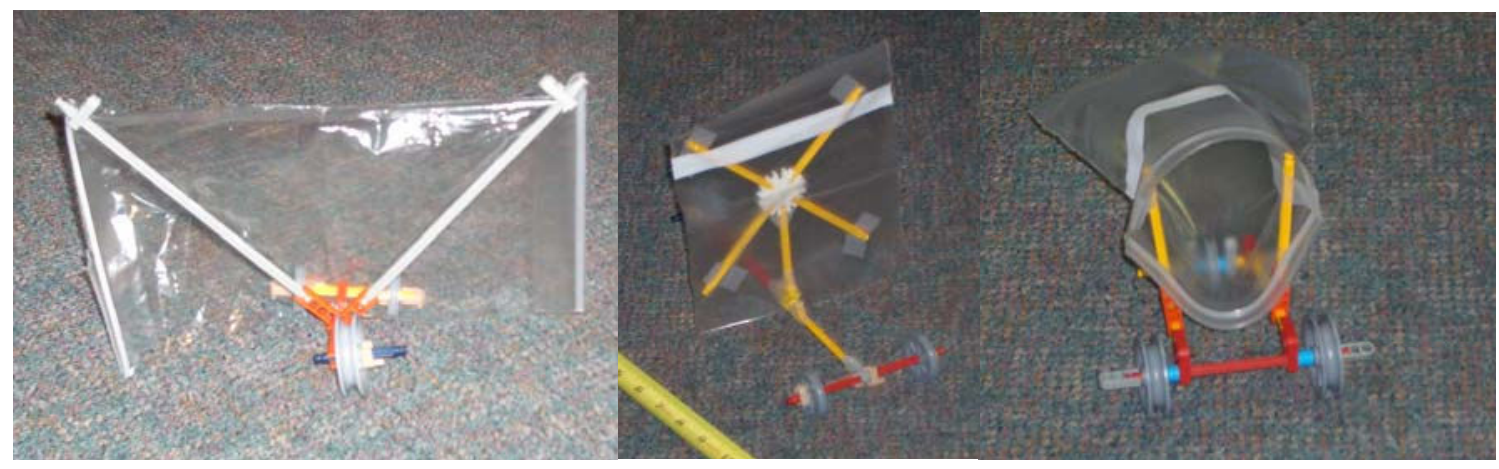

Figure 3: Some of the sail vehicle designs.

\section{Power and Energy Conversion: An Engineering Perspective}

Dr. Gary Bayles, founder and president of Energy Systems Design, Inc. prepared an excellent presentation on the challenges that engineers face in developing systems which harness energy, store energy, transport energy and convert energy into useable forms. He stressed that future engineering students (like the students participating in the YESS program) will determine the 'quality of life' for their lifetime. Relating to the seminar topic, the mini design challenge which was adapted from an activity from the Teach Engineering website, ${ }^{11}$ was to develop an understanding of the transfer of energy and to determine work and power.

\section{Power It Up!!!}

The objective was to design and construct a waterwheel that would raise the maximum weight in the shortest possible time. The teams were only allowed to use the following materials: an empty 2-liter plastic bottle with $1 / 2$-inch holes drilled in each end, $3 / 8$-inch wooden dowel rod, 16 index cards, 48 inches of string, one roll of masking tape, and scissors. At the end of the construction time, each team was allowed to test their mechanism using the following materials: 2 quarts of water, funnel, weight (each team was allowed to select their desired weight in 50 to 500 gram increments) and a stop watch. The "bragging rights" was POWER. Some of the designs are shown in Figure 4. 


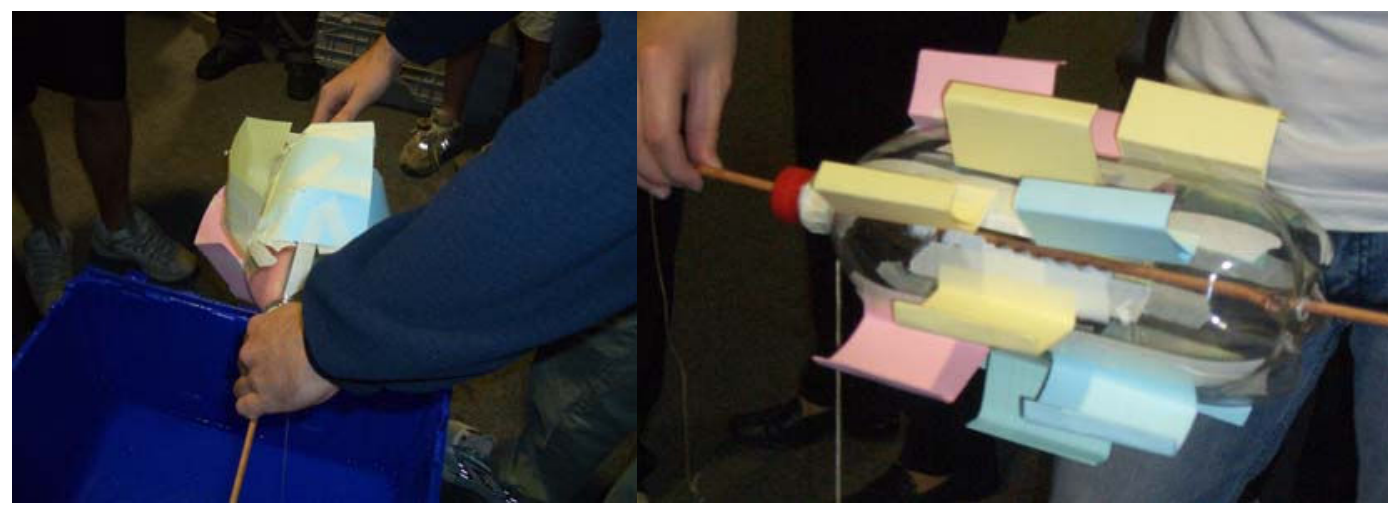

Figure 4: Some unique waterwheel designs.

\section{Mathematical Modeling}

Dean Sheridan, an engineering teacher and mathematical modeling consultant from Glenelg High School and co-leader of the YESS program, provided an excellent overview of the usefulness of mathematical modeling in engineering. An overview of the necessary equations to predict the performance of a mousetrap vehicle was also presented. The mini design challenge for this week's seminar made use of a mousetrap in order to familiarize the students with its performance. Figure 5 illustrates some of the designs for the Mousetrap Pull challenge.

\section{Mousetrap Pull}

The challenge was to construct a device that pulls a load across an open space. Mousetrap blocks were given to each team, along with a wire hanger, string, masking tape, axles and pulleys. Holes were drilled into the block so that the teams could insert axles and pulleys in different positions. The 'bragging rights' for this project was distance $\boldsymbol{x}$ mass. Each team was limited to three tests, so they were required to choose their weight carefully for each of their tests. The best score was entered for the competition. In addition, no portion of the block or weight could leave the ground/carpet (to ensure that the weight was not launched during the test).

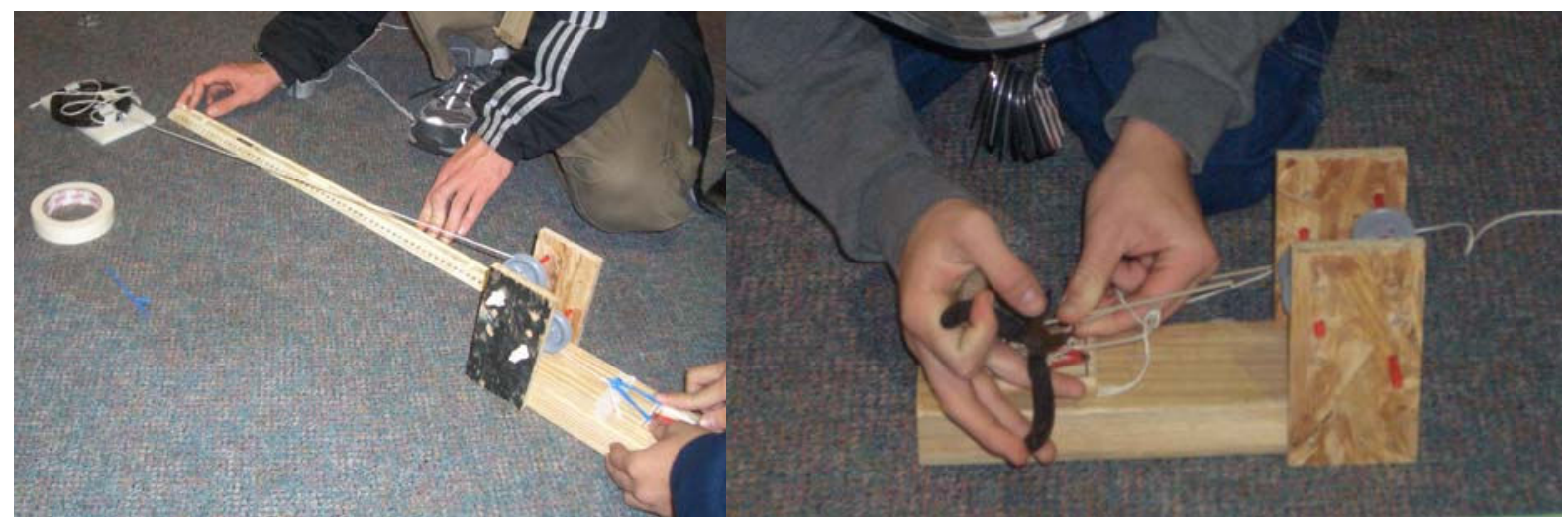

Figure 5: Mousetrap Pull competition. 


\section{The Mousetrap Vehicle Design Project}

During the next seminar, the teams worked on finalizing their designs and worked on predicting their vehicle performance to ensure that it would qualify in each of the four categories. The design testing took place on December 14, with many innovative designs. One of the winning designs is shown below in Figure 6.

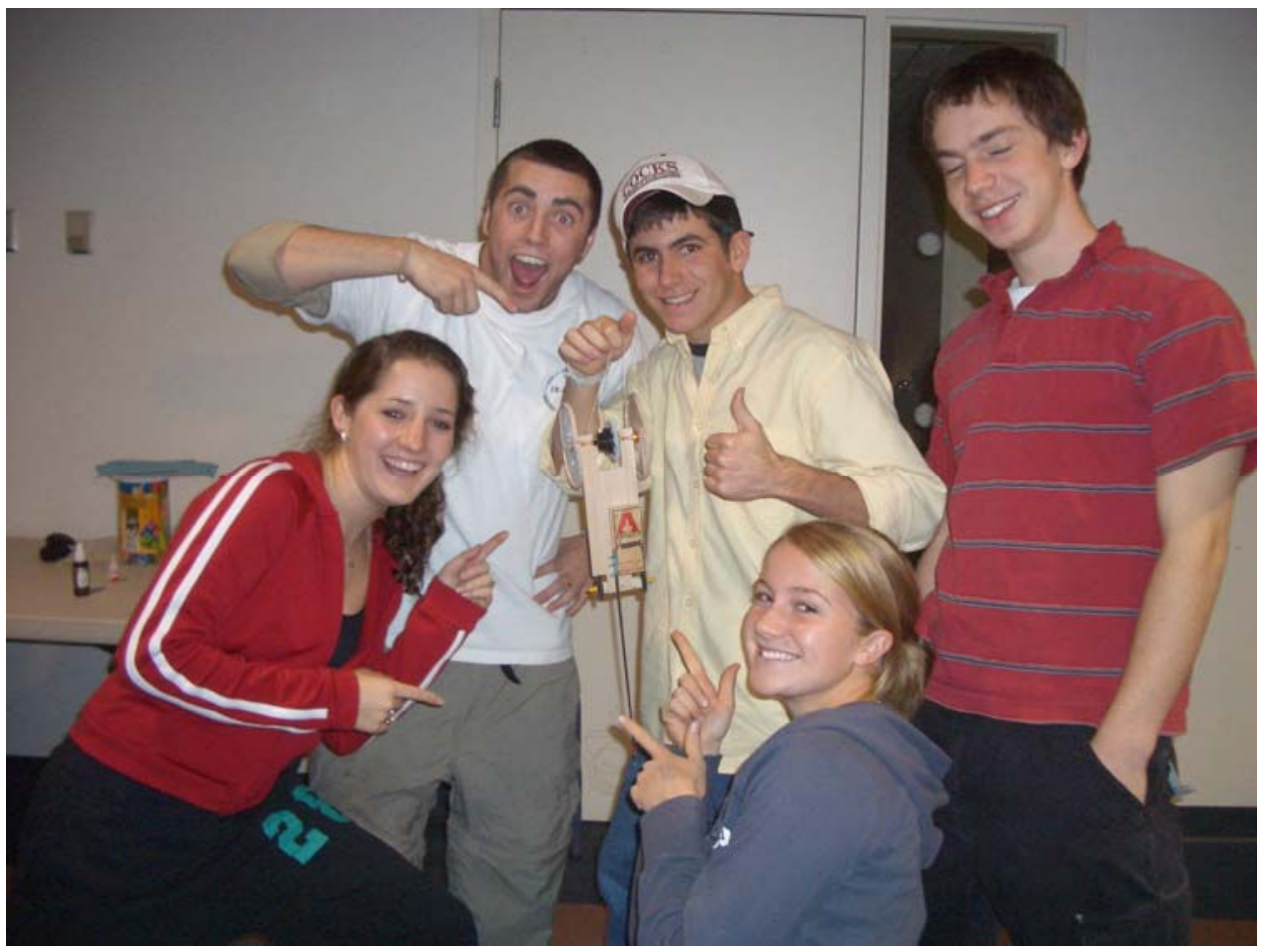

Figure 6: Team BBAMM with their winning mousetrap vehicle design.

\section{Results and Conclusions}

The Board of Directors of the Historical Electronics Museum met during summer 2004 to strategize how to improve the erratic attendance of the Young Engineers and Scientists Seminars program. The attendance in the 2003-4 program ranged from 23 to 55 students per seminar, with only one student attending all of the seminars. The program was subsequently reformatted to be a hands-on program with an over-aching design project enhanced with mini design challenges held during each seminar. The attendance in the 2004 program ranged from 50 to 72 students (with an average of 63 students at each session). Eleven students attended all of the seminars, and fifty students attended at least two-thirds of the seminars during the 2004 YESS program. In addition, there were 10-15 visitors (high school teachers and parents) at each seminar. At the design project testing, each of the eleven students with perfect attendance received a $\$ 50 \mathrm{gift}$ card to Best Buy ${ }^{\mathrm{TM}}$. Monetary awards were also made to the top three design teams (based on the hot air balloon project bragging rights), in the amount of $\$ 800, \$ 600$ and $\$ 400$ per team respectively. This format was continued during the 2005 YESS program, with a new design 
project, and new seminars and mini design challenge activities. The attendance in the 2005 program ranged from 57 to 90 students (with an average of 75 students at each session). Twenty four students attended all of the seminars, 78 students attended the majority of the seminars and 108 students attended at least two of the seminars. The twenty-four students with perfect attendance received Best Buy ${ }^{\mathrm{TM}}$ gift cards. The four highest scoring teams in the design competition received awards of $\$ 800, \$ 600, \$ 350$ and $\$ 250$, respectively.

The Board of Directors of the museum has expressed their delight with the improved attendance of the YESS program over the last two years. Comments from many of the students and parents during the YESS program indicated that the hands-on activities and the design project were enjoyable additions to the seminars.

As a pilot effort to assess the effectiveness of the YESS program, student participants completed surveys at the middle and end of the seminar series. The instruments were designed to capture changes in student interest in science and engineering as well as a host of related attitudes and confidence levels related to math, science, and engineering of interest to the seminar designers. At this time, preliminary results of the pre and post surveys are included below. In addition, a third survey will be sent to each of the YESS student participants (during the month of May) to determine if the YESS program has influenced what they plan to study when entering college. The design notebooks will also be reviewed, and these results will also be presented.

Most of the students expressed strong or very strong interest in YESS (82\%) at the beginning of the experience. Many of the participants attended the 2004 seminar series and their enthusiasm for YESS may have been influenced by their experiences the year before. At the end of the 2004 program $84 \%$ of the students rated their enthusiasm for YESS as strong or very strong. By the end of the 2005 YESS program, 95\% of the students rated their enthusiasm for YESS as strong or very strong. In response to, "Overall, I learned a lot in this seminar series," $77 \%$ agreed or strongly agreed. As another sign of satisfaction, students were asked if they would recommend this program to a friend. Eighty-seven percent agreed or agreed strongly with this statement.

The seminar is reaching students from a wide range of families as reflected in parental occupations. Of particular interest to the seminar designers was whether students coming from families with a parent or parents who work in an engineering or technical field held different expectations or claimed different knowledge compared to students whose parents work in nontechnical fields. Of the respondents to the pretest, $25 \%$ indicated that their mothers were in a technical field and $39 \%$ of the fathers. Four students are in both counts because both mother and father are in technical careers. There was no difference between groups of students based on parental occupation on their interest in an engineering career, their knowledge of science and engineering fields, their plans to major in science or engineering in college, or whether their interest in science is related to becoming a doctor or other health professional. A few more students with parents who are not in engineering or a technical field feel pushed into science or engineering field rather than being motivated by their interest. These students also claim greater knowledge of science and engineering careers than their peers.

On the posttest instrument, students indicated whether their skills or interest increased, stayed the same, or decreased on a number of items based on their participation in the seminar series. Results are shown in Table 1 and are presented as the percent of students indicating each response. 
Table 1: Student Response to Post Survey Skills or Interest

\begin{tabular}{|l|c|c|c|}
\hline Statement & $\%$ Increased & $\%$ Decreased & $\%$ Same \\
\hline $\begin{array}{l}\text { My interest in pursing a career in science } \\
\text { or engineering has: }\end{array}$ & $63 \%$ & $2 \%$ & $35 \%$ \\
\hline My interest in teamwork has: & $61 \%$ & $7 \%$ & $32 \%$ \\
\hline My ability to work on teams has: & $65 \%$ & $2 \%$ & $33 \%$ \\
\hline $\begin{array}{l}\text { My confidence in successfully studying } \\
\text { science or engineering in college has: }\end{array}$ & $65 \%$ & & $35 \%$ \\
\hline $\begin{array}{l}\text { My understanding of how math helps } \\
\text { solve problems in science and engineering } \\
\text { has: }\end{array}$ & $67 \%$ & & $33 \%$ \\
\hline $\begin{array}{l}\text { My knowledge of science and engineering } \\
\text { fields has: }\end{array}$ & $78 \%$ & $22 \%$ \\
\hline
\end{tabular}

The responses of the 20 students who completed the pretest and the posttest surveys were analyzed using a paired sample t-test. On only two survey items was there a statistically significant difference between the two administrations of the survey. Students reported a statistically significant increase in their level of understanding of the connection between math and science and engineering $(\mathrm{t}=-3.80, \mathrm{p}<.05)$ and a statistically significant increase in the level of agreement with the statement: I expect to major in science or engineering in college $(\mathrm{t}=\mathrm{-}$ $4.36, \mathrm{p}<.05)$. In general, the differences in means from the pretest to the posttest were in the expected direction or remained stable, but no other changes were statistically significant.

In addition, a brief constructed response (BCR) type question was also part of the pre and post survey. The students were asked to describe how a mouse trap vehicle works, and what influences a mousetrap vehicle that is built to (i) maximize distance traveled or (ii) maximize the load that it can pull or (iii) maximize speed or (iv) achieve specified stopping distance. The students were asked to appropriately use as many of the following terms as possible; which included: potential energy, kinetic energy, friction, motion, mechanical advantage, length of lever arm, torque, gearing, wheel-to-axial ratio and transmission. Scoring of these questions was based on a rubric that listed key points student responses should include, and to reduce bias pre and post scoring was done by the same individual. Preliminary data demonstrate that student knowledge improved from pre to post test, with scores increasing $16 \% \pm 5 \%$. These improvements demonstrate that this program is effective at targeting understanding of how a mousetrap vehicle works. However, overall average scores on understanding and design concepts were lower than anticipated.

One methodological concern in measuring changes in confidence and knowledge with a group of students selected for their talents in math and science is the risk of a ceiling effect. If interest and knowledge are high prior to an intervention, it is difficult for the intervention to demonstrate any statistically significant positive effect. In some cases, students' self-rated levels of confidence or knowledge decreased from the pretest to the posttest. The authors speculate that these trends may reflect a renewed appreciation for the complexity of science and engineering fields and a healthy reassessment of their expertise after the seminar series. They thought they knew a great deal at the start of the program, but the seminar series expanded their understanding such that 
they now know that their knowledge is more tentative and incomplete. Survey questions (for the final survey for this program, which will be administered in May) are being designed to determine if this interpretation has merit.

\section{Acknowledgement}

The authors wish to acknowledge the financial support for this program from Northrop Grumman and the Historical Electronics Museum; the National Science Foundation for our

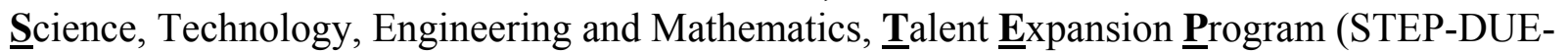
0230148), and funding of a mini-grant from the NSF funded Conducting Rigorous Research Education: Creating a Community of Practice (DUE-0341127).

\section{Bibliographic Information}

1. Marks-Persinger, K.D., Editor, Reflections, The Historical Electronics Museum Newsletter, Volume 13, Issue 3, Fall/Winter 2003.

2. $\quad$ Bayles, T.M. "Improving the Freshman Engineering Experience", Proceedings of the 2004 American Society for Engineering Education Annual Conference \& Exposition, paper 2004-1602. Presented in the Freshman Programs Division Session \#2253 at the ASEE Annual Conference, Salt Lake City, UT, June 22, 2004.

3. http://www.yesshem.com, accessed September 15, 2005.

4. $\quad$ Bayles, T.M., A.M. Spence and J. Brown Leonard, "YESS - Young Engineers \& Scientists Seminars" Paper \#1378 published in the Proceedings of the 2005 American Society for Engineering Education Annual Conference \& Exposition. Presented in the K-12 Engineering \& Pre-College Outreach Session \#1510 at the ASEE Annual Conference, Portland, OR, June 13, 2005.

5. Foster, T., "YESS Fall Program", Reflections, The Historical Electronics Museum Newsletter, Volume 15, Issue 1, Winter 2005.

6. Silverstein, D.L. "Who Wants to be an Engineer?", Proceedings of the 2003 American Society for Engineering Education Annual conference \& Exposition, presented in the ASEE Multimedia Session \#2793 at the ASEE Annual Conference, Nashville, TN, June 24, 2003.

7. $\quad$ http://www.asme.org, accessed September 7, 2005.

8. Bayles, T.M., Spence, A.M. and C. Morrell, "Science, Technology, Engineering and Mathematics Talent Expansion Program: A Focus on Diversity", Proceedings of the 2003 American Society for Engineering Education Annual Conference \& Exposition. Presented during the Recruitment \& Outreach in CHE Session \#2213 at the ASEE Annual Conference, Nashville, TN, June 24, 2003.

9. Brand, J.I., "The Effective Use of Logbooks in Undergraduate Classes," Chemical Engineering Education, vol. 33, no. 3, 1999, pp. 222-231.

10. http://www.umbc.edu/sae/minibaja.html, accessed October 19, 2005.

11. http://teachengineering.com, accessed October 26, 2005. 